American Journal of Applied Sciences 6 (6): 1225-1234, 2009

ISSN 1546-9239

(C) 2009 Science Publications

\title{
Environmental Factors Influence on Mobile Learning Business
}

\author{
${ }^{1}$ Alireza Nasiri and ${ }^{2}$ Guishi Deng \\ ${ }^{1}$ University of Tehran, Tehran, Iran \\ ${ }^{2}$ Dalian University of Technology, Dalian, China
}

\begin{abstract}
Problem statement: Recently, there has been growing interest in m-learning consequently emerging m-learning technology is promising technological and educational business. Nevertheless, $\mathrm{m}$-learning is a new business and the different actors are still trialing by ways of a diversity of business models to overcome in able to achieve a sustainable and profitable place in this market. Numbers of $\mathrm{m}$ learning products providers do not succeed in supplying m-learning products. In this situation not only a suitable business model is vital but also environmental and external factors have impact on mobile learning business model. Overall objective of this study was to survey the business model framework of m-learning with effect of external and environmental factors. Approach: Methodical approach was based on a classification of m-learning actors and its environmental factors. Based on this, we analyzed case studies description and developed main environmental factors that constitute the m-learning environment. Factors were summarized in morphological boxes and then through out its three steps result came up. Results: The results indicated technology, market and regulation are three major environmental factors which were forcing m-learning business model and business model should react to changes of these three factors to keep sustainable business. The research further argued the external factors of m-learning environment in order to understanding and developing the m-learning business and the ways these factors influence the business model of m-learning as well. Conclusion/Recommendations: M-learning business is based on many factors such as technology, changes in society, educational drivers, demand for flexible learning and the new learning paradigm but only three major drivers(technology, market and regulation) had considerable effect on m-learning business model and should be taken into account as a result if they change business model should be changed.
\end{abstract}

Key words: External forces, environmental drivers, business model, influence on business model

\section{INTRODUCTION}

In recent years, there has been great interest in the potential for mobile learning. Some providers of $\mathrm{m}-$ learning components achieve profits by offering $\mathrm{m}-$ learning products. They are likely to become key players in the field of m-learning. Others developing with the same or even more efforts do not succeed in supplying m-learning products.

For a successful business and superior positioning in the marketplace a suitable business model is essential to put m-learning products on a commercially utilizable basis. The business model is part of a comprehensive $\mathrm{m}$-learning strategy. A business model aligns a strategic task for an m-learning provider as well as an economical dimension and an m-learning strategy has to consider a pedagogical and a technical dimension too $^{[15]}$.
Business and business model environment in practice are not static, m-learning business like the other electronic and telecommunication businesses put into practice in a rapid change environment and market, this business changes maybe ascribed to internal forces, they are caused by external events too, such as entry of new players on the market, standardization of new technologies and shifting regulatory regimes, so it is in evitable to revise business strategy and business model over the time to react to the changing of technology, market and regularity conditions ${ }^{[22]}$.

External factors effect on the corporations operations and business activities as well. As result mlearning providers should monitor their business environment that to react them and change their own business model.

Usually external factors considerably are out of control and can only be dealt with to the best of the

Corresponding Author: Alireza Nasiri, International Cultural Exchange Office, Dalian University of Technology, Dalian City, Liaoning province, China, 116024 Tel: +86-13478701203 Fax: +86-41184708897 
company's aptitude. However they affect the decisions a company have control on. Therefore, a company should distinguish changes in the business environment with the purpose of tapping the new opportunities in the market. In order to help m-learning providers to recognize m-learning environmental factors in this study, we will survey some of the environmental factors that may impact market conditions, or how technology impacts business model. Companies are required to consider all main elements of the environment, which comprise the social, economic, political and legally, technological, competitive and institutional environment.

New opportunities and threats are generated through the environmental changes. This can directly affect the business model ${ }^{[23]}$.

The term business model is perhaps the most discussed and least understood term in electronic commerce $^{[29]}$ and thus in mobile commerce as well. Over the past few years the field of business models has developed from defining business models, via discovering business model components and sorting out business models into categories, to developing descriptive models. First it is significant to consider what a business model is.

A business model describes the way a company or network of companies aims to make money and create consumer value ${ }^{[16]}$. The literature provides three different approaches in dealing with this complex fact. However, most classifications tend to be based on new opportunities offered by the Internet ${ }^{[1]}$ and wireless and mobile alternatives. It is clear that technology is an important driver for the reconsidering of business models. There are several basic elements of a business model.

The most current research frameworks are then analyzed, depicting a maturing research domain. Finally, m-learning specific business models are discussed.

It is clear that in the domain of information communication technology based innovations, like mlearning, interdependencies between involved elements at the supply and the demand side and environmental elements as well as in the interaction between them, lead to critical mass and network externality issues ${ }^{[3]}$.

Unfortunately there is lack of research for mlearning business models.

As literature review shows the business models have discussed in this area are not included relations between external factors of business and business model but business is not happening in vacuum, most of literature takes a static view on business models.

Without consideration about external factors which influence business models may it is not practical business model, in practice business models should be dynamic, especially in the domain of ICT and mobile technologies.

Devoid of concerning relation between environmental factors and business model, it is difficult to realize what is occurring in business area, what opportunities appearing or threat emerging in business.

An opportunity is the chance to introduce a new product or service that can generate superior returns. Opportunities can arise when changes occur in the external environment. Many of these changes can be perceived as threats to the market position of existing products and may necessitate a change in product specifications or the development of new products in order for the firm to remain competitive. The SWOT analysis summarizes the external environmental factors as a list of opportunities and threats.

Changes in the external environment may be related to: Customers, competitors, market trends, suppliers, partners, social changes, new technology and economic environment, political and regulatory environment.

This research studies what kind of external drivers are forcing business models. Based on our results, technology, market and regulation have great influence on business model in dynamic environment.

\section{MATERIALS AND METHODS}

The methodical approach is based on a classification of m-learning actors and environmental forces. Describing the m-learning dynamic business model in react to the external factors influence is deduced. This study used the case study literature describing approach which is especially appropriate for obtaining complex details and novel understandings about a specific fact under investigation. But we don't have enough case studies on m-learning business models so in order to provide a dynamic framework for m-learning business models we decided to choose the elearning, m-learning and mobile technology areas to understand the m-learning environment and environmental forces because e-learning and mobile technology have the most similar elements to the mlearning.

We first searched for m-learning, mobile technology and e-learning business and researches such as papers and reports. Then we categorized all materials into e-learning, m-learning and mobile technology, further dividing each category into case studies and report and literature review. Next we identified and classified relevant environmental forces and changes by 
considering the m-learning, mobile technology and elearning business environment and dynamic character of business models by integrating dynamic and adaptability concepts as well as external factors influence which can be used to describe the change of business models.

As a result external forces have been detected in $\mathrm{m}$ learning environment.

Based on this, we analyzed case studies description and developed three main environmental factors that constitute the m-learning environment. During the data collection and case analyzing the external forces were refined.

The factors are summarized in morphological boxes. This method is based on a three step process of negation and construction. In the first step, the phenomenon has to be decomposed. This decomposition leads to a number of characteristics that make up all possible ways of comprehension. In the second step, all possible or relevant realizations are determined. Using the method in problem solving like the specification of a business model, the third step is the reconstruction whereby the user selects one or more realizations for each characteristic.

\section{RESULTS}

Environmental drivers: Many companies fail to monitor and act on economic trends that may signal opportunities or threats. This research particularly in dynamic business environment such as electronic and its related business like telecommunication, IT, elearning and m-learning where ignoring environmental factors change may lead to go bankrupt.

Environmental factors evaluation is important and useful specially when used to recognize the external factors influences, drivers and barriers on a business.

Nonetheless, in the environment of business model, all factors may not be relevant.

Mainly the impact of technological developments, market and regulation issues have a direct influence on m-learning business model.

Technological developments are important because m-learning is mostly based on technological innovation. Besides technological developments and regulatory issues, market dynamics are important in business modeling context. Furthermore regularity and standards such as education policy, market regulations and technological and telecommunication standards also play an important role ${ }^{[13]}$.

In our previous research we proposed a static business model for m-learning. Based on an extensive literature review, we selected the following six basic business components in m-learning area for our business model framework: Learner or user, government, content, telecommunication, device and service.

The pentagon's sides in the framework represent business model components in m-learning area. The circle which is located in the center of pentagon shows the learner who is targeted in business.

In the recent research we intend to propose a dynamic business model which is result of effect of environmental forces on previous static model by incorporating business model, dynamics.

A graphical framework of the m-learning business model is shown in Fig. 1.

Figure 1 shown that business model is which has represented by the pentagon is surrounded by environmental factors which may directly influence the business models.

For this purpose we apply three external forces as main environmental factors. These to vast extent are similar to the factors of phasing model as described by Macinnes ${ }^{[14]}$.

In business model's environment the following three kinds of external influences have been classified: market such as growing interest for mobile learning, technological innovations as an example of the emergence of new technology like WiMAX and regulatory and standards influences for example the influences of governmental that regulate business with legislation.

It is important to mention that our importance classifications as shown in the framework currently are just hypotheses and have not been thoroughly tested yet.

This discussion indicates dynamic change on $\mathrm{m}$ learning business model caused from environmental changing force and means act and position of every business actor in dynamic environment is influencing with environmental change on technology, market and regulation.

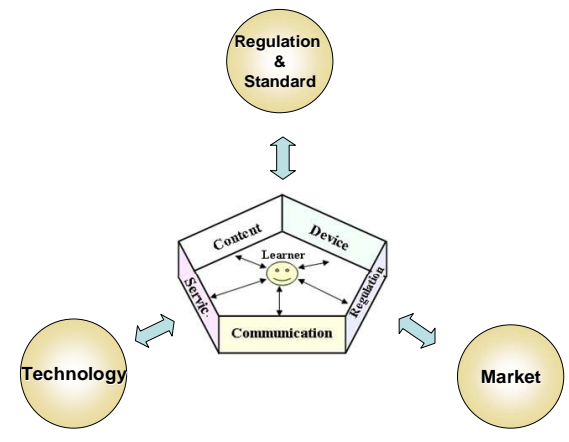

Fig. 1: Environmental drivers influence on m-learning business model 


\section{DISCUSSION}

M-learning technological drivers: Technology acts as a mediator between input and outputs which create new products or services ${ }^{[31]}$. M-learning is an undeveloped area, so far its power and potentials has not been completely discovered. Obviously the majority of computer users only employ a narrow proportion of accessible technology to them ${ }^{[19]}$. Keegan has noticed the mobile device has been available for a several years without significant attention to its capability for education ${ }^{[9]}$. Nonetheless learning technologies are changing continuously and new learning and related technology emerging in the market day after day.

Usually new technologies are dealt with on the shallow without wide understanding of their complete potentials $^{[15]}$.

Shifting technology definitely can have a grave impact on a business and emerging new technologies is great driver in technology based business like mlearning.

Significant change of technology includes changes in center of capabilities ${ }^{[20]}$. These effects on business drivers and capabilities should be taken into account in the development of new business opportunity.

Technology drives the most powerful changes of a business model in development of a new business model.

With reference to the technological aspect, handheld devices, content and wireless access technologies are the most important drivers forward the change in m-learning business models ${ }^{[28]}$.

Nowadays new devices which are able to support various formats of content with concurrently support different access technologies are rising in the $\mathrm{m}$ learning marketplace. Today, several access technologies provide Internet access to all kind of learners via mobile handsets. Position of mobile phone, handheld devices and telecommunication providers are changing in market and new technologies are entering to m-learning market. Current handheld manufacturers and telecommunication operators loose their market share chance if they do not employ the potential of new technologies ${ }^{[32]}$.

Technological encourage using m-learning: There are some expected benefits from using the mobile devices into the learning courses. These benefits are ${ }^{[15,16]}$ :

- SMS can be used to get information more easily than phone calls or email

- PDAs or other holding devices are light and easy to carry
- Can take notes directly into the device during outdoor lessons, either typed, handwritten or voice

- Using the infrared function of a PDA, or a wireless network such as Bluetooth

- Can be used anywhere, anytime

- Stylus pens and handwriting are much more natural than using keyboard and mouse

We can add some more benefits to their list as well:

- Educational institutions' flexibility in the face of rapid change

- Affordable and available connectivity

- Availability of appropriate devices

- Interoperability

Telecommunication technology of m-learning: For mobile hardware to engage in the mobile learning environment it is necessary for these devices to have access to m-learning content, often located on a network resource. The combination of mobile hardware with mobile technology is what allows this phenomenon to progress ${ }^{[4]}$.

Mobile network operators probably play the most important role in enabling m-learning. Carriers provide widespread communication services to students. Mobile network operators for providing services need to cooperate with Internet Service Providers (ISP). ISPs supply available internet network access to end users.

Wireless Application Protocol (WAP) is an internationally arranged standard that facilitates students to access to the internet using WAP-enabled mobile phones.

WAP enabled phones support the students to communicate via sending of text blocks and voice. Technological progresses are moving beyond WAP and SMS and currently are launching much more reliable access whilst displaying more graphical information.

The Wi-Fi Technology employs radio waves which communicate mutual. The radio transmission occurs at frequencies of $2.4 \mathrm{GHz}$ or $5 \mathrm{GHz}$, which is greatly higher than the frequencies used for cell phones. The higher frequency permits the signal to transmit much more data ${ }^{[6]}$ and student can receive fast and more content.

The first of wireless standard entered to the mobile technology market was IEEE $802.11 \mathrm{~b}$. There are different standards in this area that transmit data faster such as Orthogonal Frequency Division Multiplexing (OFDM) and later Multiple-Input Multiple-Output (MIMO) uses multiple transmitter and receiver antennas in order to allow for increased data throughput through spatial multiplexing. 
Wi-Fi devices can transmit on any of the supported frequency bands and they can frequency hop between the different bands ${ }^{[12]}$.

WiMAX, the Worldwide Interoperability for Microwave Access, supports long distance communication which could be a potential solution to the suburban and rural areas where education system and internet infrastructure is hard to provide. .

A WiMAX tower can provide coverage of around 3000 square miles. This connection is more stable and is able to send much data with less error ${ }^{[30]}$.

Emerging every one of these telecommunication technologies creates new opportunities in m-learning area and can affect m-learning business players thereupon influence their business model.

Content as a driver: "Content is king" has become a famous expression to show the rising importance of content creation as an important m-learning provider market segment ${ }^{[17]}$. Content providers offer prearranged m-learning content. Content is either standardized, or personalized or individualized.

This content could be data and information products such as courses, books, may also be quizzes and examinations and so on in text, music and video formats. These contents can be used in various techniques:

Short Message Service (SMS) can be used to get information to staff and students; furthermore they can transmit text-based messages on most models ${ }^{[25]}$.

Multimedia Messaging Service (MMS) is the same as SMS but allows the users to send and receive graphics.

MP3: Audio file format that compresses audio files and enables them to be shared by users

CAM: Video cameras embedded into mobile phone and PDAs witch allows users to take and send and receive pictures

All these procedures are used in m-learning to enhance content delivery.

Transform from SMS to CAM increased content's strength and boosted tendency to use of mobile technology for learning ultimately affect m-learning business model.

M-learning devices: Device is an important element of the m-learning value net. Consequently, device manufactures are constantly striving to develop a wider variety of products ${ }^{[27]}$ since future applications and services will need innovative features to make downloading learning material easier than before in different kinds of format such as text, voice and video.

Probably the first device that comes to mind when mobile hardware is discussed is the PDA. These devices offer many of the features of a full-size laptop computer but in a package that fits in a pocket. Mobility is a primary component of $\mathrm{m}$-Learning hardware ${ }^{[4]}$ and few devices offer the combination of mobility and features that the PDA does. But in most of cases, hardware is not m-learning specific. Device manufactures therefore often supply non-m-learning segments. Special m-learning hardware can be required due to special types of data.

Most personal technologies can support mobile learning, including:

- Personal Digital Assistant, in the classroom and outdoors

- Tablet PC UMPC mobile phone, camera phone and Smartphone

- Learning Mobile Author, e.g., for authoring and publishing WAP, J2ME and Smartphone

- Personal audio player (MP3 and MP4) is the most widely used file format for audio content e.g., Students can listen to audio tutorials, books and lectures

- Handheld audio and multimedia guides, in museums and galleries

- Handheld game console, modern gaming consoles such as Sony PSP or Nintendo DS

Technical and delivery support for mobile learning:

- 3GP For compression and delivery method of audiovisual content associated with Mobile Learning

- Wi-Fi gives access to instructors and resources via internet

- General Packet Radio Service (GPRS) is an always-on internet service, mobile data service, provides high speed connection and data transfer rate

- Bluetooth is a wireless short-range communications technology that can be used to transfer data between Bluetooth-enabled devices, for example the PDA in the student hand can pick up messages from the mobile in his bag

- 4G: fourth-generation mobile telephone technology. When implemented, $4 \mathrm{G}$ will be the successor to $3 \mathrm{G}$ 
Every new generation of mobile handheld device play different role in m-learning value net and makes change on m-learning business model

Technological innovations: Whilst technological change, questions about next and new generation of technology are on the desk.

Relatedly, Conole while considering founding technology of m-learning as well asks questions such as: What are the new and emerging technologies and how can they be used to support learning and teaching?

What learning platforms are being used and how do they compare?

What are the emerging new software and hardware systems?

How can we explore mobile and smart technologies? And what ways are in-built tracking mechanisms within m-learning systems giving rise to surveillance issues? ${ }^{[5]}$ Answer to each above question may affect m-learning business model.

M-learning market: M-learning as one of the latest education and training method seems to be the fastest developing in education market compare to the traditional even e-learning market which is pushed by market and pushed business strategists and educational institutions to increase the m-learning trend ${ }^{[24]}$.

But business can not be devised without an understanding of the needs of potential customers of valued added m-learning ${ }^{[18]}$.

It may be useful to consider some learners with particular learning and mobility needs separately, like those that are traveling and would, at the same time, like to learn, those who have no access to schools or a web based learning educational system, or those who need urgent learning, such as healthcare. Companies whose staffs spend their time out of their office and who have training needs, or universities and schools which need m-learning as a complement for their education method or as a part of value net all use mlearning.

The scope of mobile learning which help the supplier understand the market and focus on to gain the large quota of market includes:

- Children and students using handheld computers, PDAs or handheld voting systems in a classroom or lecture room

- Students using mobile devices in the classroom to enhance group collaboration among students and instructors using a Pocket PC
- On the job training for someone who accesses training on a mobile device "just in time" to solve a problem or gain an update

- Learning outdoors, for example on field trips

- The use of personal technology to support informal or lifelong learning, such as using handheld dictionaries and other devices for language learning. Improving levels of literacy, numeracy and participation in education amongst young adults

- To provide audiovisual support in order to enhance training that has been provided in a corporate business or other classroom environment

- Cultural educational drives increasing the mlearning demand and pushing the market to use mlearning as much as possible

Some of cultural education habits that increase mlearning demand are following:

- Valuing informal learning, hobbies and skills (self-directed learning)

- The changing culture of the learner to digital learning

- Appetite for access to information and communication on demand

- Changes in the culture of education

- Economic well-being

- Life-long learning

- Increasing student numbers in home education

- Globalization of teaching and learning

- High flexibility, personalized and individualized learning

Market climate: The existing business atmosphere for mobile learning products and services could be more favorable. The market is growing at a five-year Compound Annual Growth Rate (CAGR) of $27.3 \%$ and will reach $\$ 1.5$ billion by 2011 .

A enormous number of user; increasing number of handheld devices on the market; powerful operating systems and applications in terms of functionality and features create strong growth conditions for mobile learning suppliers which is a great driving the adoption of mobile learning ${ }^{[26]}$.

There are several major growth factors driving the mobile learning market:

- The concept of anytime/anywhere excites the marketplace

- On-the-job training is frequently targeted as the area most suited to the application of m-learning, irrespective of the particular market niche 
- There are strong proponents of the notion that developing countries could find m-learning attractive simply because of the ubiquity of the mobile phone

- While there is a lot of experimentation in various niche markets, there appears to be an absence of comparative cost analysis

- The majority of people live in deep rural areas in developing countries such as China and Africa with little or no fixed line telecom infrastructure where everyone can have a mobile phone ${ }^{[11]}$

- Content publishers and content service suppliers are aggressively converting legacy content and developing new multimedia Mobile Learning content

- The rapid evolution of powerful convergent and connected wireless handheld devices with mobile Web browsers

- The availability of advanced mobile operating systems, robust mobile application software and rich client interfaces

- User interface technology that overcomes the limitations of the small device footprint of most handheld devices

Market condition: The global m-learning sector encompasses approximately thousands of participants contributing every possible method of m-learning. No single participant in the e-training (m-learning and elearning) market accounts for $5 \%$ market share or more. Recognizing their inefficiencies, market participants have started to consolidate ${ }^{[24]}$.

A study discovered, providers compete inside etraining segments where there is only little competition among the different market segments ${ }^{[21]}$.

Regarding the demand of the m-learning, it can be discovered that m-learning products are in a different range used in all learning sectors. The demand is not only huge but also diverse.

M-learning products not only are demanded by educational institutions or companies but also by individual and autonomous learners focusing special learning objectives ${ }^{[8]}$.

In US the largest buyers are the local and state followed by consumers. The single largest vertical demand is in the healthcare industry.

The largest revenue opportunity for suppliers throughout the forecast period is the demand for Mobile Learning packaged content. The second largest revenue opportunity for suppliers is the demand for content development services and content conversion services $^{[26]}$.
In general learners pay for education but some learners are not used to pay extensive fees for educational technology such m-learning. Payment for education, especially for technology based learning, depends on social and cultural contexts and backgrounds. Suitable revenue sources must to have alternative options and consider these aspects. Moreover, it has to be taken into account that who use the m-learning products is not always the one who chooses implements or pays for it ${ }^{[16]}$.

Despite seems, the technology is main source of change in m-learning business models, but the market is taking a active role as well and technology is adopted by markets ${ }^{[10]}$.

The main concerns of learners should always be reflected in the business model. Learners' priorities have a natural tendency to change therefore business models should be dynamic and can't be inflexible ${ }^{[13]}$.

Regulations and standards: Regulatory has great impact in development process of m-learning and the market development guides the most when business model is set for established market ${ }^{[2]}$.

In addition to regularities, standardization effects m-learning business model as an environmental driver. Standards tend to define the technology selection. Delay in standards can also delay the change in business models.

M-learning regulation and standards is a companion document to the m-learning education and training system and drive the way m-learning can be used in teaching and learning. The m-learning regulations cover a general strategy and road map for m-learning and its standards cover topics such as display resolutions, storage, telecommunication protocols, memory and processor capacities of digital mobile devices and outline what could be considered default specifications for hardware and software for mobile devices and supporting technologies.

M-learning regulations and standards seek to guide the decision-making process easier for teachers and developers by providing information addressing the nature of mobile devices and the baseline standards that optimise their use ${ }^{[16]}$.

Regulation systems affect business model by setting the lawful structure which provides the people and the market with a broad choice of competitive mlearning services. Government sets a general regular educational environment by setting market precept, education policy, legislation and degree validation and so on and standardization groups set the disciplinary environment with a variety of technical standards. 
Regulation appears in many types, through the design of the software, moderation of internet chat, commercial intervention of advertisements and promotions and self-regulation of the online community, fair competition, telecommunication regulation, deregulation, security and customer protection, intellectual property rights and content regulation and privacy can support a change on business models. It should be noted that regulation also can activate opportunities for a development of new products and services as well as basic business models.

It also seems that the regulation is always coming late and it can slow down or fasten the change of business models for ${ }^{[32]}$.

Every one could claim that de/regulation was one of the motives that initiated the innovation movement of the wireless subsequent developed m-learning industry.

The liberalization of telecommunication markets began in the late 1980s in a few developed countries with a larger number following the privatization and liberalization trend throughout the $1990 \mathrm{~s}^{[2]}$.

May can be called the inception of the next development in e-learning is attributed to m-learning.

Policies associated in the United Kingdom led to open tenders and a seeking for improved services and better value for government money.

As well it happened in the United States of America led to the breaking of monopolies, especially for the new cellular licenses ${ }^{[10]}$.

Later the Japanese Ministry of Post and Telecommunications started the deregulation of the market by permitting users to own the handset devices in $1994^{[2]}$.

This slight alteration in regulation opened market development as well as technological opportunities and telecommunications became consumer driver.

These cases obviously demonstrate the impact of the de/regulation on a company's business models ${ }^{[2]}$.

From the standard perspective the M-standards are organized into the following topics: Client platforms, mobile content development, mobile content delivery and mobile content support. These basic principles standards push decision making in applying m-learning standards then influence m-learning value net and business model ${ }^{[16]}$.

\section{CONCLUSION}

M-learning reduces the barriers of time, place and distance and provides learning opportunities to individual learners, companies and institutions. Is there really a global m-learning demand with billions of dollars worth or it is only because of a powerful marketing?

All forecasts have the same opinion on the growth of m-learning market therefore it can not be caused only by a forceful marketing strategy.

A several factors are source of practical and rational answer to this question. Technological and economical derivers; change in culture of learning; emerging the demands of urgent learning; pedagogical advantages; globalization of teaching and learning and the commercial and business aspect of m-learning as opportunities are some of the specified factors.

Therefore, m-learning business is based on many factors such as technology, changes in society, educational drivers, demand for flexible learning and the new learning paradigm ${ }^{[7]}$ but only three major drivers(technology, market and regulation) have considerable effect on m-learning business model and should be taken into account, if they change business model should be changed.

\section{ACKNOWLEDGMENT}

This research was supported by a grant from the National Foundation Science Committee in China (70671016).

\section{REFERENCE}

1. Afuah, A. and C.L. Tucci, 2003. Internet Business Models and Strategies, Text and Cases. 2nd Edn., McGraw-Hill, New York, ISBN: 0072511664.

2. Bouwnman, H. and I. MacInnes, 2006. Dynamic business model framework for value webs. Proceedings of the 39th Hawaii International Conference on System Sciences, Jan. 04-07, IEEE Xplore Press, USA., pp: 43. DOI: 10.1109/HICSS.2006.131

3. Bouwman, H., T. Haaker and H. De Vos, 2008. Mobile Service Innovation and Business Models. Springer, Heidelberg, ISBN: 978-3-540-79237-6, pp: 41.

4. Caudill, J.G., 2007. The growth of m-learning and the growth of mobile computing: Parallel developments. Int. Rev. Res. Open Dist. Learn., 8. http://www.irrodl.org/index.php/irrodl/article/view/ 348/873

5. Conole, C., 2004. E-learning: The hype and the reality. J. Interact. Media $n$ Educ., wwwjime.open.ac.uk/2004/12/conole-2004-12.pdf

6. Forouzan, B.A., 2004. Data Communications and Networking. 3rd Edn., McGraw Hill, New York, ISBN: -10: 0072923547, pp: 973. 
7. Heinz, A.K., 2001. Corporate universities: Lessons in building a world-class work force. IEEE Trans. Eng. Manage., 48: 112-113. DOI: 10.1109/TEM.2001.913173

8. Johnson, G. and K. Scholes, 2002. Exploring Corporate Strategy-Text and Cases. 6th Edn., Prentice Hall, Harlow, Essex, ISBN: 0273651129, pp: 1120.

9. Keegan, D., 2005. The incorporation of mobile learning into mainstream education and training. Proceedings of the 4th World Conference on MLearning, Oct. 25-28, SA., pp: 1-17. http://www.mlearn.org.za/CD/papers/keegan1.pdf

10. Keegan, D., 2005. Mobile learning: The next generation of learning.

http://learning.ericsson.net/mlearning2/files/workp ackage 5/book.doc

11. Keegan, D., 2007. Mobile learning: The latest development of distance learning. EADL Conference Westbury Hotel, May 24-24, Dublin, pp: $1-15$.

http://www.ericsson.com/ericsson/corpinfo/programs/res ource_documents/dkeegan_eadl_24_may_2007.pdf

12. Keegan, D., 2007. The future of learning, From elearning to m-learning.

http://learning.ericsson.net/mlearning2/project_one /book.html

13. Kijl, B., H. Bouwman, T. Haaker and E. Faber, 2005. Developing a dynamic business model framework for emerging mobile service. http://userpage.fuberlin.de/ jmueller/its/conf/porto05/papers/Kijl_Bo uwman_Haaker_Faber.doc

14. MacInnes, I., 2005. Dynamic Business model framework for emerging technologies. Int. J. Servic. Technol. Manage., 6: 3-19. DOI: 10.1504/IJSTM.2005.006541

17. Mohammad, I.S., M. Hosany and R. Gianeshwar, 52006. A Mobile-E-learning (M-E) adaptive architecture to support flexible learning. Malaysian Online J. Instruct. Technol., 3: 19-28. http://myais.fsktm.um.edu.my/1633/

16. O'Connell, M. and J. Smith, 2007. A guide to working with m-learning standards A manual for teachers, trainers and developers, Version 1.0, Commonwealth of Australia 2007. http://estandards.flexiblelearning.net.au/docs/m-standardsguide-v1-0.pdf

17. Ök, D., G. Hoppe and M.H. Breitner, 2004. Business model for e-learning. Proceeding of the Conference on E-Learning: Models, Instruments, Experiences of the Multikonferenz Wirtschaftsinformatik, Mar. 9-11, Essen, Germany, pp: $\quad 1-7 . \quad$ http://www.iwi.unihannover.de/publikationen/dp-287.pdf
18. Parsons, D., H. Ryu and M. Cranshaw, 2006. A study of design requirements for mobile learning environments. Proceeding of the 6th IEEE International Conference on Advanced Learning Technologies, pp: 96-100. DOI: 10.1109/ICALT.2006.1652376

19. Muyinda, P.B., 2007. M-learning: Pedagogical, technical and organizational hypes and realities. Campus-Wide Inform. Syst., 24: 97-104. DOI: 10.1108/10650740710742709

20. Prahalad, C.K. and G. Hamel, 1990. The core competence of the corporation. Harvard Bus. Rev., DOI: 10.1007/3-540-30763-X_14

21. Research, B., 2001. Wachstumsmarkt E-Learning Anforderungen, Akteure und Perspektiven im deutschen Markt.

http://www.berlecon.de/output/studien.php?we_obj ectID $=20$

22. Reuver, M., H. Bouwman and I. MacInnes, 2007. What drives business model dynamics? A case survey. Proceeding of the 8th World Congress on the Management of eBusiness, July 11-13, IEEE Xplore, USA., $\quad$ ep: 2-2. http://ieeexplore.ieee.org/xpls/abs_all.jsp?arnumbe $\mathrm{r}=4285301$

23. Roberts, B. and M. Toleman, 2006. E-business processes and factors of influence: One model does not fit all. Proceeding of the 10th Pacific Asia Conference on Information Systems, July 6-8, Kuala Lumpur, Malaysia, pp: 1-8. http://www.pacis-net.org/file/2006/1185.pdf

24. Seufert, S., Book Rethinking Management Education E-Learning Business Models Strategies, Success Factors and Best Practice Examples. http://elearningreviews.org/seufert/docs/elearningbusniess-models-book.pdf

25. Safaa, S. and A. Mahmoud, 2008. Proposed model for distributing e-courses content through mobile technology architectures. Proc. World Acad. Sci. Eng. Technol., 27: 1-16. http://www.waset.org/pwaset/v27/v27-48.pdf

26. Adkins, S.S., Ambient Insight's The US Market for Mobile Learning Products and Services: 2006-2011 Forecast and Analysis. http://www.ambientinsight.com/Reports/MobileLe arning.aspx

27. Sharples, M., 2007. Big issues in mobile learning. Report of a Workshop by the Kaleidoscope Network of Excellence, Mobile Learning Initiative, University of Nottingham. http://www.lsri.nottingham.ac.uk/msh/Papers/BIG_ ISSUES_REPORT_PUBLISHED.pdf 
28. Sanz-Velasco, S.A., 2007. Technology and business model learning leading to growth: Startup ventures in mobile internet. Int. J. Technoentrepreneurship, 1: 35-57. DOI: 10.1504/IJTE.2007.013268

29. Timmers, P., 1998. Business models for Ecommerce. Elect. Market., 8: 3-8.

30. Trifonova, A. and M. Ronchetti, 2006. Mobile learning: Is anytime + anywhere $=$ always online? Proceeding of the 6th International Conference on Advanced Learning Technologies, July 5-7, IEEE Computer Society, USA., pp: 702-706. DOI: 10.1109/ICALT.2006.1652539
31. Tushman, D.L. and P. Anderson, 1986. Technological discontinuities and organizational environments. Administrat. Sci. Q., 31: 439-465. http://eric.ed.gov/ERICWebPortal/custom/portlets/ recordDetails/detailmini.jsp?_nfpb=true\&_\&ERIC ExtSearch_SearchValue_0=EJ347166\&ERICExtS earch_SearchType_0=no\&accno=EJ347166

32. Välimäki, J., 2006. Change of business models for wireless internet access. Proceeding of the Seminar on Networking Business, Oct. 2006, Networking Laboratory, Helsinki University of Technology, pp: 1-7. http://www.netlab.hut.fi/opetus/s383042/2006/pape rs_pdf/A2.pdf 